\title{
Imatinib mesylate inhibits in vitro and ex vivo biological responses related to vascular occlusion in giant cell arteritis
}

\author{
E Lozano, ${ }^{1}$ M Segarra,' A García-Martínez, J Hernández-Rodríguez,' M C Cid'
}

\begin{abstract}
${ }^{1}$ Vasculitis Research Unit, Department of Internal Medicine, Hospital Clínic, University of Barcelona, Institut d'Investigacions Biomèdiques August Pi i Sunyer (IDIBAPS), Barcelona, Spain; ${ }^{2}$ Emergency Medicine, Hospital Clínic, University of Barcelona, Institut $\mathrm{d}^{\prime}$ Investigacions Biomèdiques August Pi i Sunyer (IDIBAPS), Barcelona, Spain
\end{abstract}

Correspondence to:

M C Cid, Department of Internal Medicine, Hospital Clínic, Villarroel 170, 08036-Barcelona, Spain; mccid@clinic.ub.es

The results of this paper were partially presented at the 70th Annual Scientific Meeting of the American College of

Rheumatology, Washington, DC, USA, November 2006; at the 13th International Vasculitis and ANCA Workshop. Cancun,

Mexico, April 2007; and at the Annual European Congress of Rheumatology (EULAR 2007).

Barcelona, Spain, June 2007

Accepted 3 June 2007

Published Online First

21 June 2007

\author{
ABSTRACT \\ Objectives: Ischaemic complications occur in $15-20 \%$ of \\ patients with giant cell arteritis (GCA). The aim of our \\ study was to explore the effect of mesenchymal growth \\ factors expressed in GCA lesions on myointimal cell \\ responses related to the development of intimal \\ hyperplasia and vessel occlusion.
}

Methods: We developed a method to obtain primary human temporal artery derived myointimal cells (HTAMCs) based on the culture of temporal artery sections on Matrigel.

Results: Among the factors tested (platelet-derived growth factor (PDGF)-AB, fibroblast growth factor (FGF)-2, vascular endothelial growth factor (VEGF), epidermal growth factor (EGF), transforming growth factor (TGF) $\beta$, chemokine (C-C motif) ligand (CCL)2, interleukin (IL)6 and (L1 $\beta)$, PDGF exhibited the strongest activity in inducing HTAMC proliferation and migration. As assessed by protein array, immunoassay and quantitative real-time reverse transcriptase (RT)-PCR, PDGF stimulated matrix proteins (collagen I, collagen III and fibronectin) as well as CCL2 and angiogenin production by HTAMCs. Imatinib mesylate inhibited PDGF-mediated activation of signalling pathways (Src, extracellular signal-regulated kinase (ERK) and Akt phosphorylation) related to cell motility and survival, efficiently resulting in inhibition of PDGF-induced HTAMC responses. Myointimal cell outgrowth from cultured temporal artery sections from patients with GCA, where multiple interactions take place, was also efficiently reduced by imatinib.

Conclusion: Among several mediators produced in GCA, PDGF has the highest vaso-occlusive potential. PDGF may also contribute to disease perpetuation by stimulating the production of angiogenic factors (angiogenin) and chemoattractants (CCL2). Imatinib mesylate strongly inhibits PDGF-mediated responses, suggesting a therapeutic potential to limit vascular occlusion and ischaemic complications in large vessel vasculitis.

Giant cell arteritis (GCA) is a chronic inflammatory disease involving large-sized and mediumsized vessels. ${ }^{1-3}$ Vascular remodelling in response to inflammation leads to intimal hyperplasia resulting in lumen occlusion and ischaemia of supplied tissues. ${ }^{47}$ In GCA, the most frequent and devastating ischaemic events occur in territories supplied by carotid and vertebral artery branches, and include ischaemic optic neuritis and stroke. ${ }^{8}$ About $10-15 \%$ of patients also develop an occlusive vasculopathy involving large-sized and medium-sized vessels, particularly the aortic arch and limbs. ${ }^{9}$ These vascular occlusive complications may occur during the follow-up of patients who underwent a satisfactory response of classical disease-related symptoms to corticosteroid therapy. ${ }^{9}$ Moreover, when large vessel stenoses occur, response to steroids is less complete and more unpredictable and patients may require angioplasty or derivative surgery. ${ }^{9}$ Vascular occlusion is even more frequent in Takayasu disease, another large vessel granulomatous vasculitis. ${ }^{10}$ Although GCA and Takayasu disease differ in their demographic and ethnic distribution, their histopathological features are nearly identical and both diseases may share immunopathogenic mechanisms. ${ }^{21}$

Under the influence of a variety of signals, vascular smooth muscle cells (VSMC) react to injury by evolving from their quiescent, contractile phenotype to proliferating, migratory and extracellular matrix (ECM)-secreting myointimal cells, key players in the development of intimal hyperplasia and vessel occlusion. ${ }^{4712}{ }^{13}$ Expression of several factors able to stimulate proliferation of mesenchymal cells has been demonstrated in GCA lesions. These include platelet-derived growth factor (PDGF), transforming growth factor $\beta$ (TGF $\beta$ ), interleukin $1 \beta$ (IL1 $\beta$ ), IL6, fibroblast growth factor 2 (FGF-2) and vascular endothelial growth factor (VEGF), among others. ${ }^{2}{ }^{3}$ 14-16 $^{14}$ Some of these factors have also been detected in Takayasu disease. ${ }^{211}$ Most of our current understanding of the pathogenic mechanisms leading to GCA comes from studies performed in temporal artery biopsies. ${ }^{23-7}$ 54-16 $^{16}$ To gain a better understanding of the mechanisms leading to vascular occlusion in GCA, we developed a system to obtain and culture myointimal cells from temporal arteries (HTAMCs) in order to assess the effects of various mediators on biological responses related to the development of intimal hyperplasia such as proliferation, migration and ECM production.

Among the factors tested, PDGF exhibited the strongest activity in our system. Given that imatinib mesylate, an inhibitor of the tyrosine kinase activity of the oncogenic protein $\mathrm{BCR} / \mathrm{ABL}$ generated in chronic myeloid leukaemia, may also inhibit PDGF receptor-mediated signalling, ${ }^{18-20}$ we tested the effect of this compound on PDGFinduced responses in our model. We found that imatinib inhibited HTAMC biological responses related to the development of intimal hyperplasia. Our findings suggest that imatinib might be a therapeutic option to limit occlusive vasculopathy in large vessel vasculitis. 


\section{MATERIALS AND METHODS}

\section{Reagents}

Recombinant human TGF $\beta$, IL1 $\beta$, IL6, epidermal growth factor (EGF), monocyte chemoattractant protein-1 (CCL2/MCP-1), FGF-2, VEGF, purified PDGF-AB and neutralising $\mathrm{mAb}$ against PDGF receptor $\alpha$ (clone 35248) were obtained from $\mathrm{R} \& \mathrm{D}$ Systems (Minneapolis, Minnesota, USA). Imatinib mesylate (Gleevec) was kindly provided by Novartis Pharmaceuticals (Basel, Switzerland).

\section{Isolation and culture of myointimal cells from human temporal arteries}

Serial, $1 \mathrm{~mm}$ thick sections from temporal artery fragments, obtained for diagnostic purposes, were placed onto ice-cold reconstituted basement membrane Matrigel (BD Biosciences, San Jose, California, USA) and cultured in Dulbecco modified Eagle medium (DMEM) $/ 10 \%$ foetal bovine serum (FBS) at $37^{\circ} \mathrm{C}$ in $5 \% \mathrm{CO}_{2}$. HTAMCs developed from the explanted sections within 1 week (fig 1A) and reached confluence in 3 weeks. Cells were then released with trypsin/EDTA (Invitrogen), transferred to uncoated flasks, and split 1:2 upon confluence. The myointimal cell phenotype ${ }^{21}$ was verified by confirming expression of smooth muscle actin by flow cytometry and type I and III collagens by real-time reverse transcriptase (RT)-PCR as described below. In all the experimental conditions tested, cell viability was confirmed by trypan blue exclusion.

The study was approved by the institutional review board of the Hospital Clínic of Barcelona and all patients signed an informed consent.

\section{Flow cytometry analysis of $\alpha$ smooth muscle actin expression} Cells were harvested with trypsin/EDTA, gently fixed with $4 \%$ paraformaldehyde for $1 \mathrm{~h}$ at $4^{\circ} \mathrm{C}$, permeabilised with $0.2 \%$ Tween 20 in phosphate buffered saline (PBS), and incubated with a mAb anti- $\alpha$ smooth muscle actin (clone 1A4, Dako, Glostrup, Denmark) for 30 min at $4^{\circ} \mathrm{C}$, and, subsequently, with a goat anti-mouse antibody (AlexaFluor488, Molecular Probes, Eugene, Oregon, USA) for $30 \mathrm{~min}$ at $4^{\circ} \mathrm{C}$. Both antibodies were used at 1/100 dilution. Cells were analysed with a fluorescenceactivated cell sorter (FACScan, Becton Dickinson, San Jose, California, USA).

\section{Proliferation assay}

Proliferation was assessed as previously described. ${ }^{6}{ }^{16}$ Briefly, HTAMCs were plated in 96-well plates at 4000 cells/well in DMEM and incubated at $37^{\circ} \mathrm{C}$ in $5 \% \mathrm{CO}_{2}$ for 1 to 6 days, with or without addition of the above listed growth factors. These were used at concentrations ranging from $5-50 \mathrm{ng} / \mathrm{ml}$, selected on the basis of previously published data and preliminary experiments. At several time-points, cells were fixed and stained with $0.2 \%$ crystal violet (Sigma-Aldrich, Madrid, Spain) in $20 \%$ methanol for $10 \mathrm{~min}$. Wells were washed, air-dried, and solubilised in $1 \%$ sodium dodecyl sulfate (SDS). Optical density was measured at the $600 \mathrm{~nm}$ wavelength.

In some experiments, HTAMC proliferation was also assessed using the 3-(4,5-dimethylthiazol-2-yl)-5-diphenyltetrazolium bromide (MTT) assay (Promega, Madison, Wisconsin, USA), according to the instructions of the manufacturer.

\section{Migration assay}

HTAMC migration was measured in 48-well microchemotaxis Boyden chambers with $0.1 \%$ gelatin-coated, $10 \mu \mathrm{m}$ pore polyester filters (Poretics, Osmonics Inc., Minnetonka, Minnesota, USA). HTAMCs were placed at 5000/well in the upper chambers. Growth factors were loaded at various concentrations in the bottom chamber of quadruplicate wells. After $6 \mathrm{~h}$-incubation in $5 \% \mathrm{CO}_{2}$ at $37^{\circ} \mathrm{C}$, cells were removed from the upper surface and filters were fixed with methanol and
Figure 1 Isolation, culture and identification of human temporal artery myointimal cells (HTAMCs). A. Primary HTAMC outgrowth from temporal artery rings cultured on Matrigel for 10 days $(100 \times$ magnification). B. Typical appearance of confluent HTAMCs grown on uncoated flasks $(200 \times)$. C. Expression of $\alpha$ smooth muscle actin by flow cytometry. D. Kinetics of HTAMC growth in Dulbecco modified Eagle medium (DMEM) $+10 \%$ foetal bovine serum (FBS) (3-(4,5-dimethylthiazol-2-yl)-5diphenyltetrazolium bromide (MTT) assay).
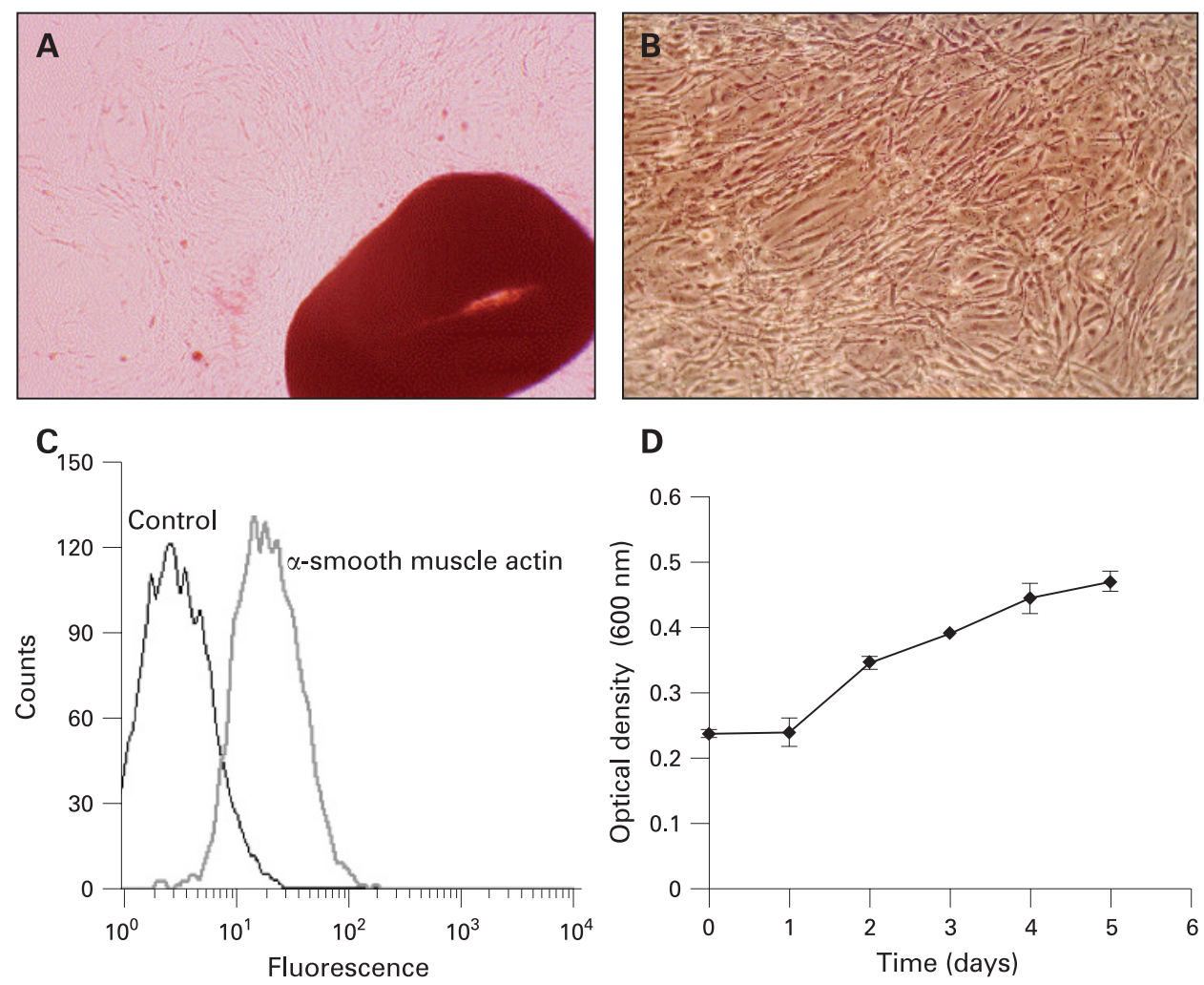
stained with haematoxylin. Cells in five randomly selected fields/well were counted under a microscope at $125 \times$ magnification.

\section{Western blot analysis}

Assessment of protein phosphorylation by Western blot was performed as described. ${ }^{22}$ Briefly, cell lysates were obtained in modified radioimmunoprecipitation assay (RIPA) buffer and supplemented with protease inhibitors (Complete, Boehringer Mannheim, Mannheim, Germany) and $\mathrm{Na}_{3} \mathrm{VO}_{4}$ at $200 \mu \mathrm{M}$. A total of $20 \mu \mathrm{g}$ of protein per lane was subjected to SDSpolyacrilamide gel electrophoresis (PAGE) (8\%) and blotted onto nitrocellulose membranes (Invitrogen, Carlsbad, California, USA). Blocked membranes were incubated overnight at $4^{\circ} \mathrm{C}$ with rabbit anti-human Src, Akt, or ERK phosphorylated at different residues. Immunodetection was performed with horseradish peroxidase (HRP)-conjugated goat anti-rabbit antibody at 1:2000 dilution. Blots were stripped and re-probed with rabbit anti-human Src, Akt and ERK antibodies. All primary antibodies were from Cell Signaling Technology (Beverly, Massachusetts, USA) and were all used at 1:1000 dilution.

\section{Assessment of protein secretion by protein array and immunoassay}

A Quantimatrix ELISA kit (Chemicon, Temecula, California, USA) was used to measure fibronectin in HTAMC supernates and cell lysates. A custom RayBio Human Cytokine Antibody Array (RayBiotech, Inc. Norcross, Georgia, USA) was designed to compare release of 30 inflammatory mediators of interest in the supernates of PDGF-stimulated vs control HTAMCs. CCL2 and angiogenin concentrations in HTAMC supernates were quantified with specific ELISA kits (Quantikine, R\&D Systems, Minneapolis, Minnesota, USA) according to the manufacturer's instructions.

\section{Quantative real-time reverse transcription (RT)-PCR}

Total RNA was extracted from cultured HTAMCs using TRIzol Reagent (Invitrogen). Total RNA (1 $\mu \mathrm{g})$ was reverse transcribed using Archive kit (Applied Biosystems, Foster City, California, USA). Collagen I (COL1A1) and III (COL3A1) mRNA were measured by quantitative real-time RT-PCR with specific predeveloped TaqMan gene expression assays from Applied Biosystems. Detailed methodological aspects have been given in previous publications. ${ }^{3} 5616$ Fluorescence was detected with an ABI PRISM 7900 Sequence Detection system and results were analysed with the Sequence Detection Software V 1.6.3 (Applied Biosystems). All samples were normalised to the expression of the endogenous control GUSb. Comparative $C_{\mathrm{T}}$ method was used to assess the relative gene expression of COL1A1 and COL3A1.

\section{HTAMC outgrowth from ex vivo cultured temporal artery sections from patients with GCA}

Temporal artery sections obtained from five untreated patients with biopsy-proven GCA and eight controls were cultured on Matrigel in the presence or in the absence of imatinib mesylate. We also tested in this system a similar size fragment of an aortic aneurysm surgically excised from a patient with GCA treated with corticosteroids for 4 years. This specimen showed mild remaining inflammatory infiltrates in the media. Daily photographs were taken from day 3 to day 17 . Outgrowth of HTAMCs was scored by two investigators blinded to the conditions tested, as follows: 1 = visible outgrowth of scattered cells; 2 = cells growing from the entire ring; $3=$ cells expanding at least two times the length of 2 ; and $4=$ cells covering the entire surface of the well. Agreement was achieved in $96 \%$ of measurements. When there was discrepancy in the first assessment, consensus was reached after re-evaluation.

\section{Statistical analysis}

Quantitative data were compared with the Mann-Whitney U test. The Kruskal-Wallis test was used for multiple comparisons.

\section{RESULTS}

\section{Culture and characterisation of HTAMCs}

After the first passage, HTAMCs were able to grow on uncoated tissue culture flasks with no addition of growth factors other than FBS (fig 1B). Flow cytometry analysis revealed a homogeneous cell population with $>90 \%$ of cells expressing $\alpha$ smooth muscle actin (fig 1C). HTAMCs doubled in 5-6 days (fig 1D) and were used for experiments between passages 3 and 6. Cells survived for at least 10 doublings with no apparent changes in cell morphology, phenotype, or growth rate. No apparent differences in morphology or growth rate could be observed between cells obtained from positive biopsies and those obtained from normal temporal arteries, indicating that proliferative and migratory activities relevant to the generation of intimal hyperplasia that occur in inflamed arteries are not intrinsic and mainly depend on stimuli present in the microenvironment.

\section{Comparative effects of mesenchymal cell growth factors on in vitro HTAMC proliferation and migration}

We next tested the effect of PDGF-AB, IL1 $\beta$, IL6, CCL2, FGF-2, TGF $\beta$, VEGF and EGF on HTAMC proliferation and migration. These factors were considered relevant candidates to provide the microenvironmental stimuli necessary for myointimal cell activation because of their known ability to stimulate mesenchymal cell proliferation and their previously demonstrated expression in GCA lesions. ${ }^{514-16}$ Among the factors tested, PDGF elicited the highest stimulation of HTAMC proliferation in a dose-dependent manner (fig 2A,B). FGF-2, IL1 $\beta$, TGF $\beta$, and EGF also induced HTAMC proliferation but to a lesser extent (fig 2A,C). PDGF-induced HTAMC proliferation was abrogated by a blocking $\mathrm{mAb}$ against the PDGF-receptor $\alpha$ (fig $2 \mathrm{~B}$ ), confirming the specificity of the response.

Given that the development of intimal hyperplasia requires not only myointimal cell proliferation but also migration towards the lumen, we explored the effects of the above growth factors on HTAMC migration in Boyden chambers. As shown in table 1, PDGF had the strongest activity in inducing HTAMC migration. Maximum activity was obtained at concentrations of 10-20 ng/ml. EGF also increased cell migration but to a lesser extent. At the range of concentrations tested, the remaining factors did not stimulate HTAMC motility (table 1).

\section{Inhibition of PDGF-induced HTAMC growth and migration by imatinib mesylate}

As shown in fig $2 \mathrm{~B}$, the effect of PDGF on cell proliferation was inhibited with a function-blocking monoclonal antibody against PDGF receptor $\alpha$. Since imatinib inhibits tyrosine kinase activity of the PDGF receptor, we tested its ability to inhibit PDGFinduced activation of signalling pathways related to cell survival, proliferation and migration in HTAMCs, given the 
Figure 2 Effect of mesenchymal growth factors on human temporal artery derived myointimal cell (HTAMC) proliferation. A. Proliferation of serum-starved HTAMCs incubated for 6 days with the displayed growth factors at $10 \mathrm{ng} / \mathrm{ml}$. B. Inhibition of HTAMCs by a function-blocking mAb against the platelet-derived growth factor (PDGF)-receptor $\alpha$, added at $10 \mu \mathrm{g} / \mathrm{ml}, 60$ min before exposure to PDGF (10 ng/ml). C. Dose response of several growth factors on serum-starved HTAMC proliferation at day 6 . Proliferation was assessed by crystal violet staining. Experiments were repeated three times and one representative experiment is shown. In all figures, symbols/bars represent mean (standard error of the mean (SEM)). ${ }^{*} p<0.05,{ }^{* *} p<0.01$ and ${ }^{* * *} p<0.001$ by Kruskal-Wallis test. D. Effect of imatinib on PDGF-induced activation of Akt, extracellular signalregulated kinase (ERK) and $\mathrm{Src}$ in HTAMCs. Western blot detection of Akt, ERK and p60Src, phosphorylated at the indicated residues, in control or PDGFstimulated HTAMCs, in the presence or absence of imatinib. Subconfluent HTAMCs were serum-starved for $24 \mathrm{~h}$, preincubated with imatinib $(1 \mu \mathrm{M})$ for 60 min and treated with PDGF-AB (10 ng/ml) for $20 \mathrm{~min}$. Blots are representative of three independent experiments.
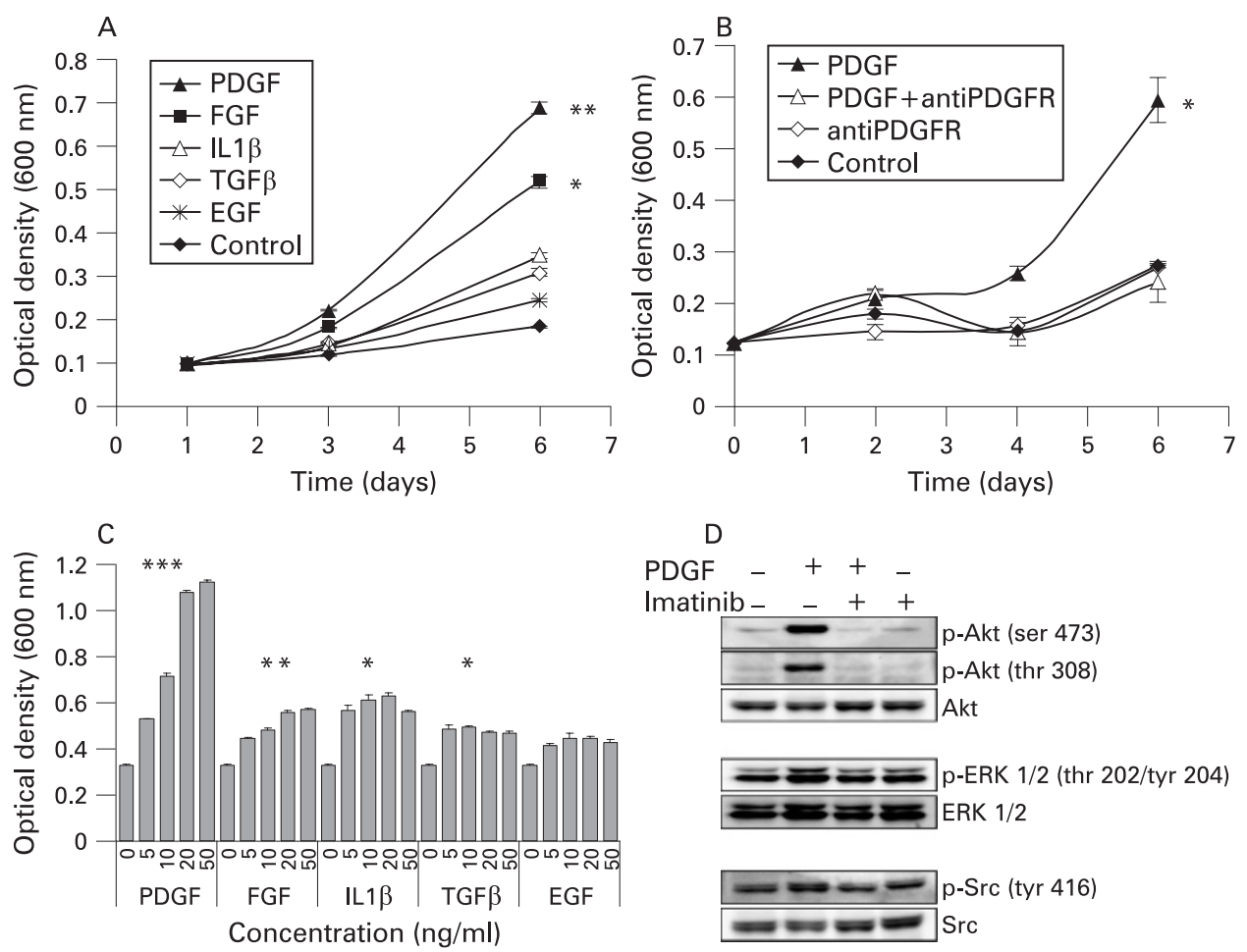

relevance of these responses in the development of intimal hyperplasia. As shown in fig 2D, treatment with PDGF resulted in an efficient activation of Akt, a pivotal enzyme transducing antiapoptotic signals, ${ }^{23}$ and Akt phosphorylation was strongly inhibited by imatinib. PDGF also increased ERK1/2 and p60 Src activation, crucial pathways in cell proliferation and migration $^{24} 25$, which decreased upon imatinib treatment.

We next assessed whether the inhibitory effects of imatinib on PDGF-activated signalling pathways resulted in an efficient reduction of HTAMC responses. As displayed in fig $3 \mathrm{~A}-\mathrm{C}$, imatinib efficiently inhibited PDGF-induced cell growth and motility. No inhibitory effect of imatinib was observed on spontaneous, FGF-2, or EGF-induced HTAMC proliferation or migration (fig $3 \mathrm{~B}$, and data not shown).

\section{Imatinib mesylate inhibits PDGF-induced extracellular matrix production by HTAMCs}

Since neointima formation requires not only myointimal cell proliferation and migration but also excessive matrix deposition, we next investigated the impact of imatinib on PDGF-induced ECM production by HTAMCs. Among potentially relevant matrix proteins, we investigated fibronectin, given its key function in supporting integrin-dependent cell proliferation and migration. We also focused on collagen I and collagen III, the major structural collagens of blood vessels. As shown in fig 3D-F, PDGF significantly upregulated soluble and cell-associated fibronectin, as well as collagen I and collagen III production by HTAMCs. These effects were efficiently reduced by imatinib.

\section{Imatinib mesylate inhibits PDGF-induced HTAMC responses related to persistence of inflammatory activity}

We investigated additional PDGF-mediated responses potentially contributing to amplify vascular inflammation in GCA. We designed an antibody-based protein array with 30 inflammatory mediators to screen for PDGF-induced molecules in HTAMCs. Mediators screened were selected according to their previously demonstrated expression in GCA or their role in the

Table 1 Migration of human temporal artery derived myointimal cells (HTAMCs) (cell number/field) in response to increasing concentrations of growth factors $(\mathrm{ng} / \mathrm{ml})$

\begin{tabular}{llllll}
\hline & $\mathbf{0}$ & $\mathbf{2 . 5}$ & $\mathbf{5}$ & $\mathbf{1 0}$ & $\mathbf{2 0}$ \\
\hline PDGF & $44(5.3)$ & $68.7(6.3)^{*}$ & $87.63(4.6)^{* *}$ & $101.4(5.0)^{* *}$ & $122.4(3.9)^{* *}$ \\
EGF & $44(5.3)$ & $66.8(1.7)^{*}$ & $77.8(6.2)^{*}$ & $79.3(3.4)^{* *}$ & $71(4.6)^{*}$ \\
VEGF & $48.6(3.5)$ & $41.6(1.6)$ & $48(3.5)$ & $50.7(2.1)$ & $47.4(2.1)$ \\
CCL2 & $48.6(3.5)$ & $47.3(4.2)$ & $37.1(2.3)$ & $47.3(3.2)$ & $49.6(3.3)$ \\
IL1 $\beta$ & $52.4(2.9)$ & $58.5(4.0)$ & $59.4(4.0)$ & $54.2(4.1)$ & $48.5(4.1)$ \\
FGF-2 & $53.7(2.4)$ & $57.1(5.1)$ & $64.6(2.6)$ & $65.1(3.0)$ & $58.8(3.6)$ \\
\hline
\end{tabular}

All values mean (standard error of the mean (SEM)). ${ }^{*} p<0.05 ;{ }^{* *} p<0.01$ by Kruskal-Wallis test.

$\mathrm{CCL}$, chemokine (C-C motif) ligand; EGF, epidermal growth factor; FGF, fibroblast growth factor; IL, interleukin; PDGF, plateletderived growth factor; VEGF, vascular endothelial growth factor. 
Figure 3 Effect of imatinib on plateletderived growth factor (PDGF)-induced human temporal artery derived myointimal cell (HTAMC) proliferation, migration and extracellular matrix production. A. Cell proliferation in response to PDGF in the absence and in the presence of imatinib (3-(4,5dimethylthiazol-2-yl)-5diphenyltetrazolium bromide (MTT) assay). Cells were serum-deprived for 24 $\mathrm{h}$, preincubated with imatinib $(1 \mu \mathrm{M})$ for $60 \mathrm{~min}$, and exposed to PDGF-AB (10 ng/ $\mathrm{ml}$ ) for 5 days. B. Cell proliferation in response to fibroblast growth factor (FGF)-2 (10 ng/ml) in the absence and in the presence of imatinib. C. Cell migration as described in the Materials and methods section. D. Fibronectin concentration in the supernates of serumfree, PDGF-stimulated HTAMCs in the presence or in the absence of imatinib. To detect cell-associated fibronectin in addition to that released to the medium, fibronectin content was also measured in cell lysates. Cell lysates and supernates were collected after 3 days of exposure to PDGF with or without imatinib.

Fibronectin concentration was normalised to cell content, assessed by crystal violet staining. Detection was performed in duplicate wells. The experiment was performed three times with equivalent results. Panels (E) and (F) show collagen I and collagen III mRNA concentrations in HTAMCs, respectively, cultured as in (A) and collected after $24 \mathrm{~h}$.
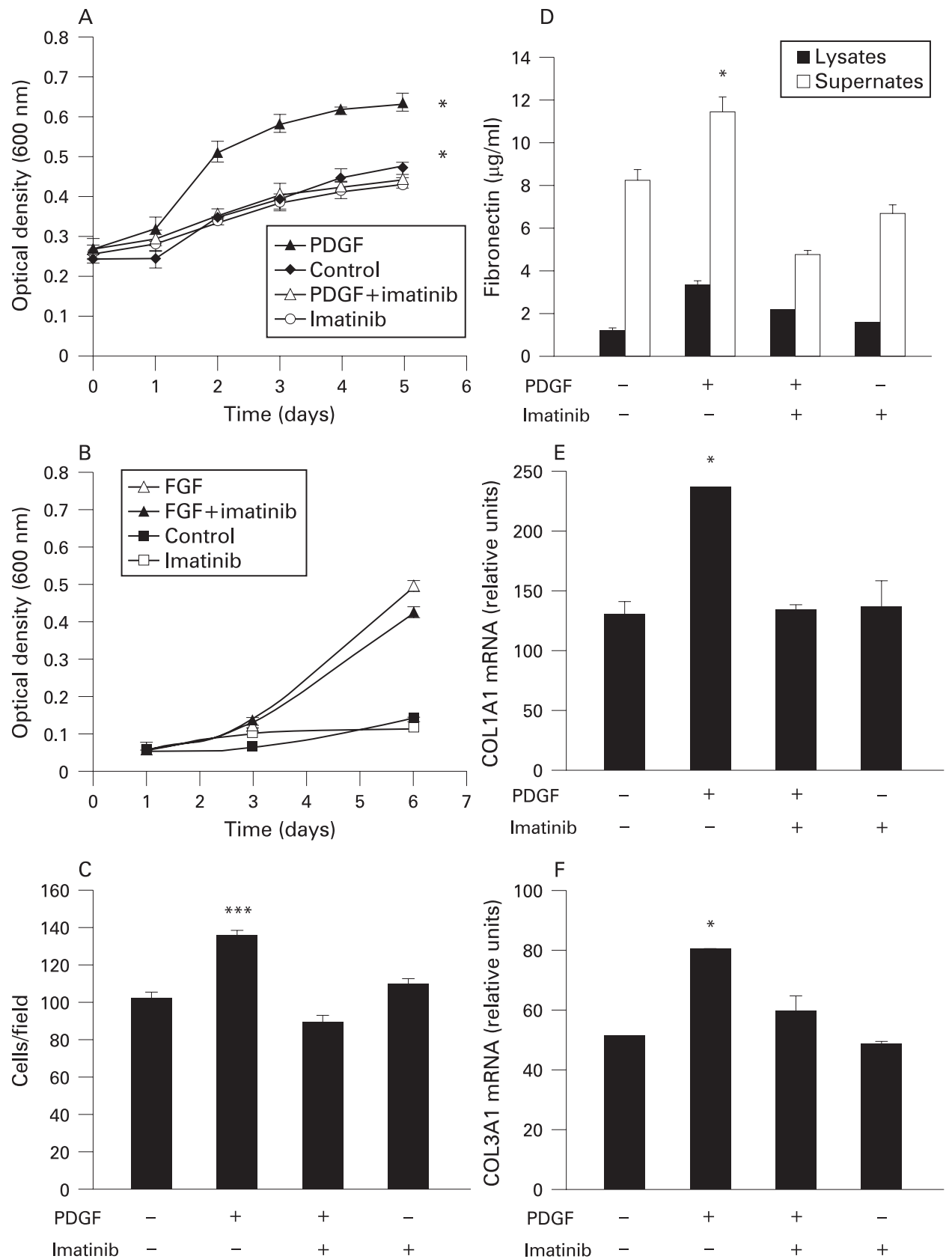

regulation of inflammatory, angiogenic, or fibrogenic responses, given that these are considered relevant in disease perpetuation or vascular occlusion (fig 4A,B). Among the surveyed factors, PDGF significantly upregulated CCL2 and angiogenin production by HTAMCs in a dose-dependent manner and this increased expression was abrogated by imatinib (fig 4C,D).

\section{Imatinib mesylate strongly reduces HTAMC outgrowth from ex vivo cultured temporal artery explants}

PDGF may not be the only factor contributing to intimal hyperplasia in GCA. In order to assess whether the inhibitory effects of imatinib on PDGF-induced HTAMC responses could be overcome by other factors present in GCA lesions, we explored the effect of imatinib on HTAMC outgrowth from cultured temporal artery sections from five patients with GCA and eight controls. As shown in fig 5, imatinib efficiently reduced, but not abrogated, HTAMC outgrowth from cultured artery sections, a complex system including multiple cell interactions and mediators. No significant differences were found between normal and GCA specimens, indicating that PDGF is a significant factor in inducing myointimal cell differentiation and growth in response to inflammatory and physical (sectioning) injury.

\section{DISCUSSION}

We successfully developed a new method to expand myointimal cells derived from thin arterial sections, using reconstituted basement membrane Matrigel as an anchorage-providing system. Our method has the advantage of requiring just a thin arterial section, which is very important since the major portion of the specimens excised must be processed to rule out or confirm the histopathological diagnosis of GCA. This system may be also applied to efficiently grow myointimal cells obtained from other vascular beds, when there is paucity of tissue or the vessels are small. Most of the studies investigating smooth muscle cell biology have been performed with cells of 
A

\begin{tabular}{|c|c|c|c|c|c|c|c|c|}
\hline & A & B & C & D & E & F & G & H \\
\hline 1 & POS & MIP-1 $\beta$ & TGF $\beta 1$ & ICAM-1 & OPG & SDF-1 & IGF-I & FGF-2 \\
\hline 2 & IL1 $\beta$ & $\begin{array}{l}\text { GM- } \\
\text { CSF }\end{array}$ & TGF $\beta 2$ & BMP-4 & OSM & $\begin{array}{l}\text { Angio } \\
\text { genin }\end{array}$ & Ang-2 & NEG \\
\hline 4 & IL1 & IL10 & TGF $\beta 3$ & PDGF & LIF & EGF & HGF & VEGF \\
\hline 6 & ra & VE & IL & $\begin{array}{l}\text { Trail } \\
\text { sR3 }\end{array}$ & IP-10 & TNF- $\alpha$ & IFN- $\gamma$ & CCL2 \\
\hline 7 & IL6 & $\begin{array}{l}\text { IL6 } \\
\text { SR }\end{array}$ & IL8 & \\
\hline
\end{tabular}

C

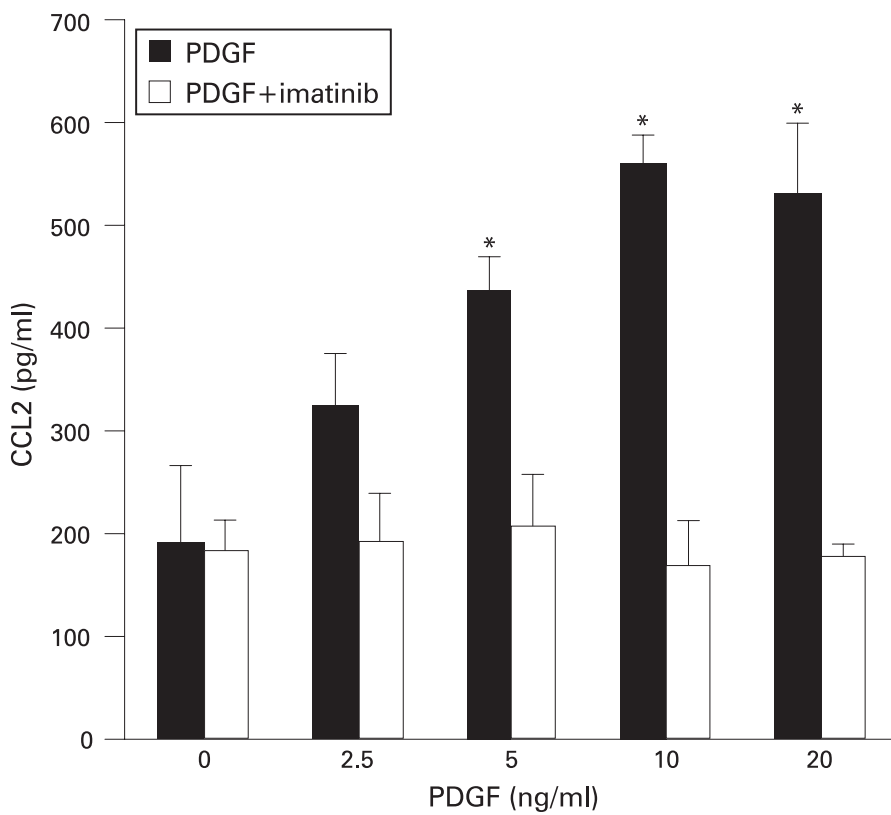

B

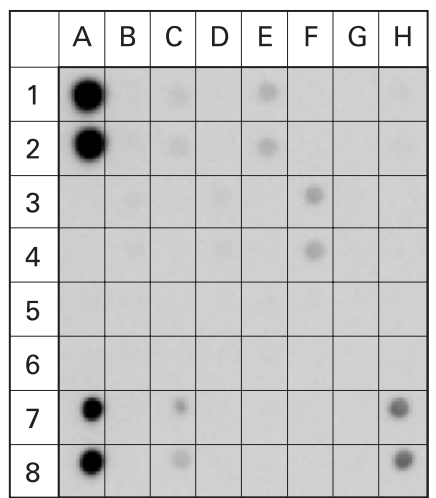

Control

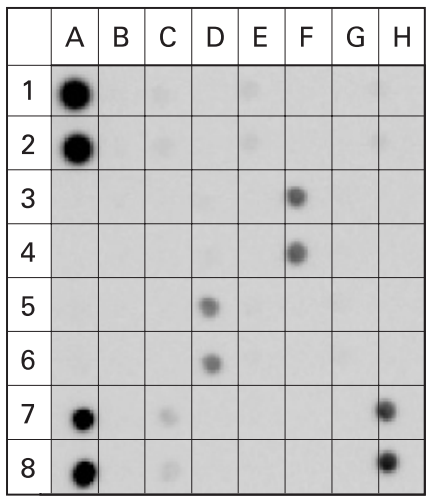

+PDGF $(10 \mathrm{ng} / \mathrm{ml})$

D

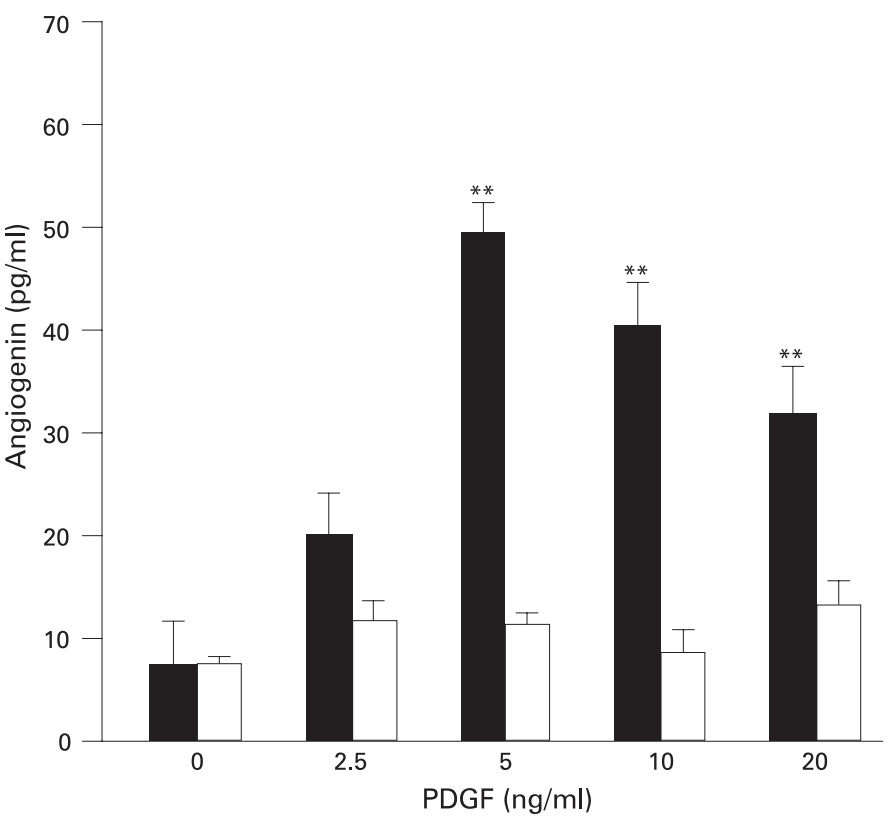

Figure 4 Effects of platelet-derived growth factor (PDGF) on chemokine (C-C motif) ligand (CCL)2 and angiogenin production by HTAMCs and inhibition by imatinib. A. Design of the array membrane where 30 mediators are detected in duplicate spots. B. Mediators were detected by protein array in serum-free supernates of human temporal artery derived myointimal cells (HTAMCs) with or without exposure to PDGF for 3 days. An increase in CCL2 and angiogenin production can be observed. Exogenously added PDGF is also detected. C,D. CCL2 and angiogenin detection in the supernates of HTAMCs incubated for 1 and 3 days, respectively, with increasing concentrations of PDGF in the presence or in the absence of imatinib (1 $\mu$ M). Results were normalised to cell number.

aortic origin or aortic explants. ${ }^{26}{ }^{27}$ Obtaining cells from targeted vessels is important because VSMCs derived from different vascular territories may have different phenotypes and functional responses. ${ }^{28}$

In this study, we took advantage of this model to explore the effects of several growth factors known to be expressed in GCA lesions on HTAMC responses related to the development of intimal hyperplasia. ${ }^{2} 35614-16$ Among the factors tested, PDGF exhibited the highest activity in stimulating HTAMC proliferation and migration. PDGF has been demonstrated to have mitogenic and chemotactic activity on cultured aortic VSMC, aortic explants and in in vivo models of arterial injury in other territories. ${ }^{26}{ }^{27} 29-31$ Based on these findings PDGF was proposed as a candidate factor involved in the development of intimal hyperplasia in GCA. ${ }^{4}$ Its expression by activated macrophages was subsequently demonstrated in GCA lesions and was shown to be associated with the development of cranial ischaemic complications and clinically symptomatic large vessel stenoses. ${ }^{14}$
Our findings functionally demonstrate that PDGF is a major growth factor for smooth muscle cells derived from arteries involved by GCA lesions.

Imatinib mesylate was specifically designed as an ATPcompetitive inhibitor of the constitutive tyrosine kinase activity of the fusion protein $\mathrm{BCR} / \mathrm{ABL}$ generated in chronic myeloid leukaemia. ${ }^{18-20}$ Imatinib was subsequently found to also inhibit the tyrosine kinase activity of c-kit, the receptor for stem cell factor (SCF) and PDGF receptor. ${ }^{19}{ }^{20}$ Imatinib is an effective therapy for patients with chronic myeloid leukaemia and patients with gastrointestinal stromal tumours bearing oncogenic mutations in the c-kit or PDGF receptors. ${ }^{19}{ }^{20}$ Given that imatinib has been used in a large number of patients with these conditions with an excellent safety profile, ${ }^{19}{ }^{32} 33$ we investigated whether imatinib could inhibit PDGF-mediated responses related to the development of intimal hyperplasia in HTAMCs. Imatinib did not show any effect on resting cells, but strongly inhibited PDGF-induced Akt, Src and ERK1/2 
A
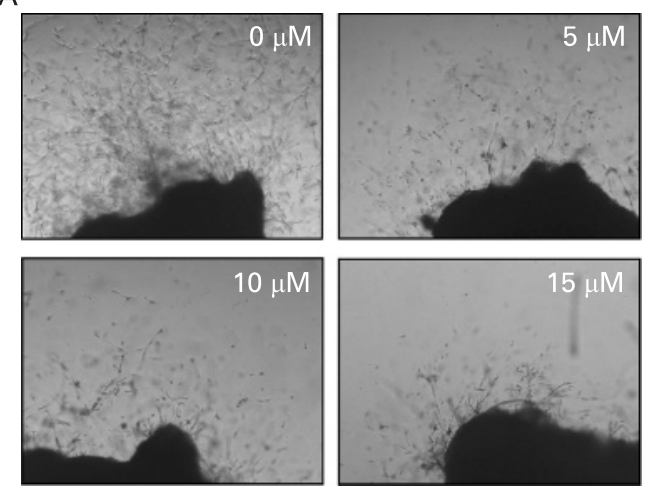

B

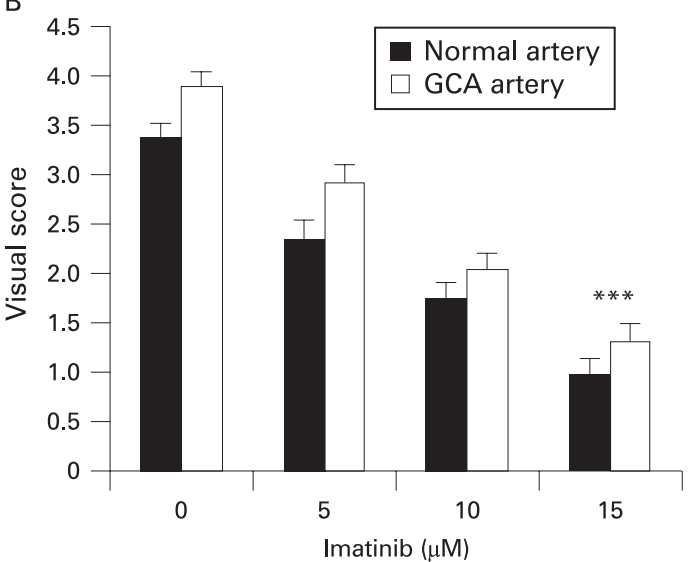

C

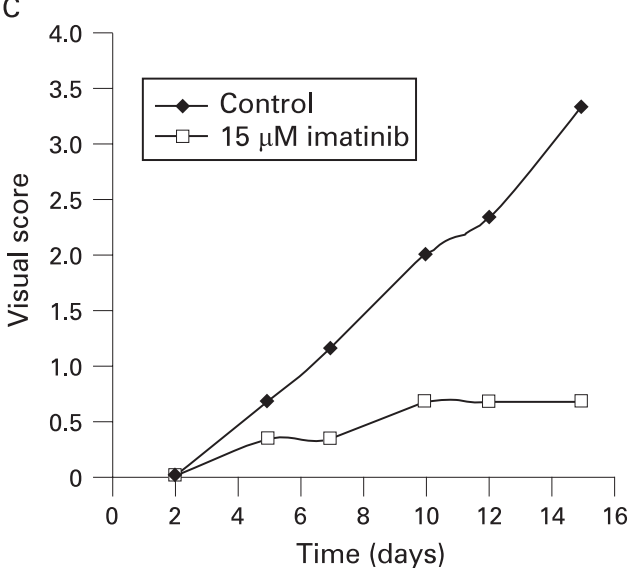

Figure 5 Imatinib inhibits human temporal artery derived myointimal cell (HTAMC) outgrowth from cultured temporal artery sections from patients with giant cell arteritis (GCA). A. Temporal artery sections exposed at the indicated concentrations of imatinib and cultured on Matrigel for 15 days. HTAMC outgrowth reaches a visual score of $4,3,2$ and 1 at imatinib concentrations of $0,5,10$ and $15 \mu \mathrm{M}$, respectively. Phase contrast microscopy $(100 \times)$. B. HTAMC outgrowth from normal (solid bars) and GCA involved (white bars) temporal artery sections exposed to various imatinib concentrations, measured at day 15. C. Effect of imatinib mesylate on myointimal cell outgrowth from an aortic fragment of a GCA-related aortic aneurysm.

phosphorylation, resulting in an efficient abrogation of PDGFinduced HTAMC proliferation and migration. PDGF also induced production of fibronectin and collagens I and III, the major structural collagens of blood vessels. Through integrin-mediated signals, fibronectin is able to support proliferation and migration of inflammatory cells and VSMC. ${ }^{13} 22$ Treatment with imatinib significantly reduced PDGF-induced fibronectin, collagen I and collagen III production, suggesting that imatinib might be useful in reducing intimal hyperplasia in GCA.

In addition to promoting fibrogenic responses, PDGF has proinflammatory effects by stimulating certain nuclear factor $(\mathrm{NF}) \kappa \mathrm{B}$-mediated responses including chemokine production by VSMC. ${ }^{26-34}$ PDGF also has an angiogenic activity in various models and induces angiogenic factors such as VEGF and FGF$2 .{ }^{17} 3536$ Together, PDGF and PDGF-induced angiogenic molecules may contribute to inflammation-induced angiogenesis, an important mechanism supporting disease persistence in chronic inflammatory diseases.

A survey of PDGF-induced molecules in HTAMCs revealed significant upregulation of CCL2 and angiogenin. CCL2 is also an angiogenic molecule and a potent chemoattractant for monocytes and $\mathrm{T}$ helper (Th)1 lymphocytes, the main components of inflammatory infiltrates in large vessel vasculitis. ${ }^{57}$ We have recently shown that increased CCL2 expression is associated with persistence of disease-activity in GCA. ${ }^{5}$ Although not fully characterised for biological functions, angiogenin has angiogenic activity in several systems. ${ }^{38} \mathrm{We}$ found that imatinib efficiently inhibited PDGF-induced CCL2 and angiogenin production by HTAMCs. Together, these findings suggest that, besides reducing intimal hyperplasia, imatinib may inhibit PDGF-driven proinflammatory activities potentially contributing to disease persistence in large vessel vasculitis.

PDGF may not be the only factor promoting myointimal cell proliferation and migration in GCA. To assess whether blocking PDGF effects could be compensated in vivo by other factors, the inhibitory effect of imatinib was tested in a temporal artery culture system. Imatinib substantially reduced, but did not abrogate, HTAMC outgrowth from cultured temporal artery explants from patients with biopsy-proven GCA. A similar effect was observed in an aortic specimen. Thus, imatinib had a strong effect in a complex system containing all the cell components and mediators participating in the development of GCA lesions. The fact that imatinib does not interfere with other factors and, accordingly, did not completely suppress HTAMC outgrowth from GCA specimens is important given that a certain extent of neointima formation may be necessary to reinforce the vessel wall, preventing dilatation and rupture. Imatinib also reduced myointimal cell outgrowth from normal temporal arteries. Taken together, these findings indicate that PDGF has a major, but not exclusive, role in driving vascular response to inflammatory and physical injury.

In summary, imatinib inhibits cell responses related to the development of intimal hyperplasia in HTAMCs and in a temporal artery organ culture, suggesting a potential therapeutic benefit in preventing the progression of vascular occlusion in stenosing large vessel vasculitis. However, in the absence of in vivo data, any therapeutic implication must be considered with caution. Testing the effects of imatinib in animal models of large vessel inflammation ${ }^{39} 40$ would add valuable information about the potential of imatinib to reduce intimal hyperplasia in vivo. Since there are no true animal models for GCA or Takayasu disease, the efficacy and safety of imatinib in reducing vascular occlusion in these diseases can only be assessed in clinical trials.

Funding: This work was supported by grants from the Ministerio de Educación y Ciencia and Fondo Europeo de Desarrollo Regional (FEDER) (SAF 05-06250), Marató TV3 06/0710 and Generalitat de Catalunya (SGR 0300/2005).

Competing interests: None declared.

Ethics approval: The study was approved by the institutional review board of the Hospital Clínic of Barcelona and all patients signed an informed consent. 


\section{REFERENCES}

1. Salvarani C, Cantini F, Boiardi L, Hunder GG. Polymyalgia rheumatica and giant-cell arteritis. N Engl J Med 2002;347:261-71.

2. Weyand CM, Goronzy JJ. Medium- and large-vessel vasculitis. N Engl J Med 2003;349:160-9.

3. Hernández-Rodríguez J, Segarra M, Vilardell C, Sanchez M, Garcia-Martinez A, Esteban MJ, et al. Tissue production of pro-inflammatory cytokines (IL-1 $\beta$, TNF $\alpha$ and IL-6) correlates with the intensity of the systemic inflammatory response and with corticosteroid requirements in giant-cell arteritis. Rheumatology (Oxford) 2004:43:294-301.

4. Cid MC. New developments in the pathogenesis of systemic vasculitis. Curr Opin Rheumatol 1996;8:1-11.

5. Cid MC, Hoffman MP, Hernández-Rodríguez J, Segarra M, Elkin M, Sanchez M, et al. Association between increased CCL2 (MCP-1) expression in lesions and persistence of disease activity in giant-cell arteritis. Rheumatology (Oxford) 2006:45:1356-63.

6. Cid MC, Hernández-Rodríguez J, Esteban MJ, Cebrian M, Gho YS, Font C, et al. Tissue and serum angiogenic activity is associated with low prevalence of ischemic complications in patients with giant-cell arteritis. Circulation 2002;106:1664-71.

7. Weyand CM, Goronzy JJ. Arterial wall injury in giant cell arteritis. Arthritis Rheum 1999:42:844-53.

8. Cid MC, Font C, Oristrell J, de la Sierra A, Coll-Vinent B, Lopez-Soto A, et al. Association between strong inflammatory response and low risk of developing visual loss and other cranial ischemic complications in giant cell (temporal) arteritis. Arthritis Rheum 1998;41:26-32.

9. Bongartz T, Matteson EL. Large-vessel involvement in giant cell arteritis. Curr Opin Rheumatol 2006;18:10-17.

10. Kerr GS, Hallahan CW, Giordano J, Leavitt RY, Fauci AS, Rottem M. Takayasu arteritis. Ann Intern Med 1994;120:919-29.

11. Noris M. Pathogenesis of Takayasu's arteritis. J Nephrol 2001;14:506-13.

12. Owens GK. Molecular control of vascular smooth muscle cell differentiation. Acta Physiol Scand 1998;164:623-35.

13. Raines EW. The extracellular matrix can regulate vascular cell migration, proliferation, and survival: relationships to vascular disease. Int J Exp Pathol 2000:81:173-82

14. Kaiser M, Weyand CM, Björnsson J, Goronzy JJ. Platelet-derived growth factor, intimal hyperplasia, and ischemic complications in giant cell arteritis. Arthritis Rheum 1998:41:623-33.

15. Kaiser M, Younge B, Björnsson J, Goronzy JJ, Weyand CM. Formation of new vasa vasorum in vasculitis. Production of angiogenic cytokines by multinucleated giant cells. Am J Pathol 1999:155:765-74.

16. Hernández-Rodríguez J, Segarra M, Vilardell C, Sanchez M, Garcia-Martinez A, Esteban MJ, et al. Elevated production of interleukin-6 is associated with a lower incidence of disease-related ischemic events in patients with giant-cell arteritis: angiogenic activity of interleukin-6 as a potential protective mechanism. Circulation 2003;107:2428-34.

17. Millette E, Rauch BH, Defawe O, Kenagy RD, Daum G, Clowes AW. Platelet-derived growth factor-BB-induced human smooth muscle cell proliferation depends on basic FGF release and FGFR-1 activation. Circ Res 2005;96:172-9.

18. Druker BJ, Tamura S, Buchdunger E, Ohno S, Segal GM, Fanning S, et al. Effects of a selective inhibitor of the Abl tyrosine kinase on the growth of Bcr-Abl positive cells. Nat Med 1996;2:561-6

19. Savage DG, Antman KH. Imatinib mesylate - a new oral targeted therapy. N Engl J Med 2002;346:683-93.

20. Noble ME, Endicott JA, Johnson LN. Protein kinase inhibitors: insights into drug design from structure. Science 2004;303:1800-5.
21. Baroni SS, Santillo M, Bevilacqua F, Luchetti M, Spadoni T, Mancini M, et al. Stimulatory autoantibodies to the PDGF receptor in systemic sclerosis. N Engl J Med 2006;354:2667-76

22. Segarra M, Vilardell C, Matsumoto K, Esparza J, Lozano E, Serra-Pages C, et al. Dual function of focal adhesion kinase in regulating integrin-induced MMP-2 and MMP-9 release by human T lymphoid cells. FASEB J 2005;19:1875-7.

23. Song G, Ouyang G, Bao S. The activation of Akt/PKB signaling pathway and cell survival. J Cell Mol Med 2005;9:59-71.

24. Playford MP, Schaller MD. The interplay between Src and integrins in normal and tumor biology. Oncogene 2004;23:7928-46.

25. Webb DJ, Donais K, Whitmore LA, Thomas SM, Turner CE, Parsons JT, et al. FAK Src signalling through paxillin, ERK and MLCK regulates adhesion disassembly. Nat Cell Biol 2004:6:154-61.

26. Marumo T, Schini-Kerth VB, Fisslthaler B, Busse R. Platelet-derived growth factorstimulated superoxide anion production modulates activation of transcription factor NF- $\kappa \mathrm{B}$ and expression of monocyte chemoattractant protein 1 in human aortic smooth muscle cells. Circulation 1997;96:2361-7.

27. Kenagy RD, Hart CE, Stetler-Stevenson WG, Clowes AW. Primate smooth muscle cell migration from aortic explants is mediated by endogenous platelet-derived growth factor and basic fibroblast growth factor acting through matrix metalloproteinases 2 and 9. Circulation 1997:96:3555-60.

28. Hoffman GS. Large-vessel vasculitis: unresolved issues. Arthritis Rheum 2003:48:2406-14.

29. Fredriksson L, Li H, Eriksson U. The PDGF family: four gene products form five dimeric isoforms. Cytokine Growth Factor Rev 2004;15:197-204.

30. Ross R, Masuda J, Raines EW, Gown AM, Katsuda S, Sasahara M, et al. Localization of PDGF-B protein in macrophages in all phases of atherogenesis. Science 1990;248:1009-12.

31. Ross R, Raines EW, Bowen-Pope DF. The biology of platelet-derived growth factor Cell 1986;46:155-69.

32. Lahaye T, Riehm B, Berger U, Paschka P, Muller MC, Kreil S, et al. Response and resistance in 300 patients with BCR-ABL-positive leukemias treated with imatinib in a single center: a 4.5-year follow-up. Cancer 2005;103:1659-69.

33. Druker BJ, Guilhot F, O'Brien SG, Gathmann I, Kantarijian H, Gattermann N, et al. Five-year follow-up of patients receiving imatinib for chronic myeloid leukemia. N Engl J Med 2006;355:2408-17.

34. Zeiffer U, Schober A, Lietz M, Liehn EA, Erl W, Emans N, et al. Neointimal smooth muscle cells display a proinflammatory phenotype resulting in increased leukocyte recruitment mediated by P-selectin and chemokines. Circ Res 2004;94:776-84.

35. Distler JH, Hirth A, Kurowska-Stolarska M, Gay RE, Gay S, Distler 0. Angiogenic and angiostatic factors in the molecular control of angiogenesis. $0 \mathrm{~J} \mathrm{Nucl}$ Med 2003;47:149-61.

36. Li X, Tjwa M, Moons L, Fons T, Noel A, Ny A, et al. Revascularization of ischemic tissues by PDGF-CC via effects on endothelial cells and their progenitors. J Clin Invest 2005:115:118-27.

37. Salcedo R, Ponce ML, Young HA, Wasserman K, Ward JM, Kleinman HK, et al. Human endothelial cells express CCR2 and respond to MCP-1: direct role of MCP-1 in angiogenesis and tumor progression. Blood 2000;96:34-40.

38. Kishimoto K, Liu S, Tsuji T, Olson KA, Hu GF. Endogenous angiogenin in endothelial cells is a general requirement for cell proliferation and angiogenesis. Oncogene 2005;24:445-56.

39. Weck KE, Dal Canto AJ, Goud JD, O'Guin AK, Roth KA, Saffitz JA, et al. Murine $\gamma$ herpesvirus 68 causes large vessel arteritis in mice lacking interferon- $\gamma$ responsiveness: a new model for virus induced vascular disease. Nat Med 1997:3:1346-53.

40. Nicklin MJ, Hughes DE, Barton JL, Ure JM, Duff GW. Arterial inflammation in mice lacking the interleukin 1 receptor antagonist gene. J Exp Med 2000;191:303-12. 